\title{
Rho GTPases are Involved on Regulation of Cytodifferentiation of SCC-4 Oral Squamous Cell Carcinoma Cell Line: A Preliminary Study
}

\author{
Nanci M Pinheiro, Anna Cecilia D M Carneiro, Virginia O Crema*
}

\begin{abstract}
Objective: This study evaluated the involvement of Rho GTPases proteins in the regulation of cytodifferentiation of the SCC-4 human oral squamous cell carcinoma cell line. Methods: Cytokeratin and vimentin immunofluorescence and F-actin staining, assays were performed with control cells and Clostridium difficile 1, 2 and $4 \mu \mathrm{g} / \mathrm{mL}$ Toxin A (Rho GTPases inhibitor) treated SCC-4 cells on three-dimensional Matrigel ${ }^{\mathrm{TM}}$ for $24 \mathrm{~h}$. Samples were analyzed by using confocal laser microscopy. Significances were $p<0.05$. Results: In all concentrations studied, Toxin A treatment decreased percentage of cytokeratin positive cells $(\mathrm{p}<0.0001)$, otherwise, it increased percentage of vimentin positive cells $(p<0.0001)$. There was a negative correlation between cytokeratin and vimentin immunoexpression $(p<0.0001)$, the higher the amount of cytokeratin, the lower the amount of vimentin. Also F-actin polymerization is affected by Toxin A treatment. Conclusion: Although this is a preliminary study, our results suggest that Rho GTPases are involved on regulation of cytodifferentiation of the SCC-4 human oral squamous cell carcinoma cell line.
\end{abstract}

Keywords: Cytodifferentiation- oral squamous cell carcinoma- Rho GTPases

Asian Pac J Cancer Prev, 21 (1), 3-6

\section{Introduction}

Patients with oral squamous cell carcinoma (OSCC) have a high mortality rate (Fazeli et al., 2011) have a poor survival, the 5-years survival rate of approximately $55 \%$ to $60 \%$ (Rhodus et al., 2014). During carcinogenesis, tumor cells undergo some modifications, such as loss of cytodifferentiation (Kalluri and Weinberg, 2009). Depending on chemical and physical properties of surrounding environment, the GTPases Rho proteins play several inter-connected functions (Sadok and Marshall, 2014).

Rho GTPases are small proteins that regulate complex biological processes such as actin cytoskeleton organization, motility, cell division among others. The Rho subfamily is made up of approximately 23 proteins and, Rho, Rac and Cdc42 groups are the best characterized (Ridley and Hall, 1992). The Rho GTPases are overexpressed in several human tumors (Svensmark and Brakebusch, 2019). The isoforms RhoA, RhoB and RhoC constitute the Rho-like group whose RhoA and RhoC promoting tumor growth while RhoB is a tumor suppressor (Jaffe, 2009). The Rac group, being Rac1 the most important isoform and, Cdc42, participate in the protrusion of lamellipodia and filopodia respectively contributing to tumor cell invasion and metastasis
(Svensmark and Brakebusch, 2019).

In cell lines of squamous cell carcinoma of the head and neck the overexpression of RhoA, Rac2 and Cdc42 GTPases in relation to normal keratinocytes has already been demonstrated (Bhave et al., 2011). This study aimed to evaluate the involvement of Rho GTPases on regulation of cytodifferentiation of OSCC cell line by using the Clostridium difficile Toxin A treatment, that glucosylates Rho proteins, inactivating all members of Rho GTPases family.

\section{Materials and Methods}

SCC-4 cell line of human oral squamous cell carcinoma of the American Type Culture Collection $\left(\right.$ ATCC $^{\circledR}$ ) obtained from the cell bank of the Federal University of Rio de Janeiro was used. Cells were grown in DMEM (Sigma-Aldrich, St. Louis, MO, USA) 1:1 HAM F12 (Invitrogen, Grand Island, NY, USA), 10\% FBS (Cultilab Campinas, SP, Brasil), $400 \mathrm{ng} / \mathrm{mL}$ hydrocortisone (Ariston, São Paulo, Brazil), 100 U/mL penicillin and $100 \mu \mathrm{g} / \mathrm{mL}$ streptomycin (Sigma-Aldrich, St. Louis, $\mathrm{MO}, \mathrm{USA}$ ) at $37^{\circ} \mathrm{C} / 5 \% \mathrm{CO}_{2}$. After defrosting of immortalized cells, cells were used in the initial passages. The experiments were performed when the cells reached at least $80 \%$ confluence. Biological triplicates and 
experimental duplicates were performed.

\section{Immunofluorescence}

$1 \times 10^{5} \mathrm{SCC}-4$ cells/well (biological triplicates) control and Clostridium difficile Toxin A - ToxA (List Biological Labs, Campbell, CA, USA) treated: 1, 2 and $4 \mu \mathrm{g} / \mathrm{mL}$ cultured on three-dimensional MatrigelTM for $24 \mathrm{~h} .4 \%$ paraformaldehyde fixed for $1 \mathrm{~h}$; incubated with: $0.2 \%$ Triton X-100 for $5 \mathrm{~min}, 3 \% \mathrm{BSA}$ for $20 \mathrm{~min}$, mouse anti-vimentin or anti-cytokeratin clone AE1/AE3 (Santa Cruz Biotechnology, Santa Cruz, CA, USA) at 1:50 overnight, Alexa-488-labelled secondary antibody chicken anti-mouse (Molecular Probes, Eugene, OR, USA) at 1:1,000 for $2 \mathrm{~h}$, rhodamine-conjugated phalloidin (Molecular Probes, Eugene, Ore, USA) at 1:100 for 30 min and DAPI at 1:500 for $15 \mathrm{~min}$.

Ten immunofluorescence images were obtained randomly at 40x with a laser scanning confocal microscope (Zeiss ${ }^{\circledR}$, Göttingen, Lower Saxony, Germany)) in order to quantify intermediate filaments that are used as a marker of epithelial cells and a marker of mesenchymal cells, cytokeratin and vimentin, respectively. Morphometry was performed by using Zen Blue software $\left(\right.$ Zeiss $\left.^{\circledR}\right)$. Nuclei DAPI stained were counted and were consider as $100 \%$. The cells stained for cytokeratin or vimentin were counted. The percentage of cytokeratin and vimentin positive cells was calculated by using Microsoft Excel ${ }^{\circledR}$ (Redmond, Washington, Estados Unidos).

Statistical Analysis
Levene's test, Kruskal-Wallis and Dunnet C post-test (vimentin), ANOVA and Tukey post-test (cytokeratin), also Correlation of Pearson were performed by using SPSS $16.0^{\circledR}$ (San Francisco, CA, USA) software and graphics with GraphPad Prism ${ }^{\circledR}$ (San Diego, CA, USA). Significance was $\mathrm{p}<0.05$.

\section{Results}

Rho GTPases are involved on regulation of cytodifferentiation of the SCC-4 human oral squamous cell carcinoma cell line

In all concentrations studied, ToxA treatment decreased percentage of cytokeratin positive SCC-4 cells $[\mathrm{F}(3,39)=62.648, \mathrm{p}<0.0001]: 75.8 \pm 11.8 \%($ ToxA $1 \mu \mathrm{g} / \mathrm{mL})$, $38.8 \pm 14.4 \%$ (ToxA $2 \mu \mathrm{g} / \mathrm{mL}$ ), $31.4 \pm 14.0 \%$ (ToxA $4 \mu \mathrm{g} / \mathrm{mL}$ ) compared to $93.5 \% \pm 4.5 \%$ of control cells (Figure $1 \mathrm{a}-\mathrm{d}, \mathrm{i}$ ). Otherwise, in all concentrations studied, ToxA treatment increased percentage of vimentin positive SCC-4 cells $[\chi(3)=29.010, \mathrm{p}<0.0001]: 48.5 \pm 20.6 \%$ (ToxA $1 \mu \mathrm{g} /$ $\mathrm{mL}$ ), $62.82 \pm 13.39 \%$ (ToxA $2 \mu \mathrm{g} / \mathrm{mL}$ ) and $80.41 \pm 11.5 \%$ (ToxA $4 \mu \mathrm{g} / \mathrm{mL}$ ) compared to $8.3 \pm 4.9 \%$ control cells (Figure 1e-g,j). There was a negative correlation between cytokeratin and vimentin immunoexpression $[\mathrm{r}=-0.77$, $\mathrm{n}=40, \mathrm{p}<0.0001$ ], the higher the amount of cytokeratin, the lower the amount of vimentin (Figure 1k).

As expected, control cells cultured in three-dimensional culture for $24 \mathrm{~h}$ showed a well-developed cytoplasm with a prominent cytoskeleton and evident cortex. Cells treated with ToxA $(1,2$ and $4 \mu \mathrm{g} / \mathrm{mL})$ showed evident

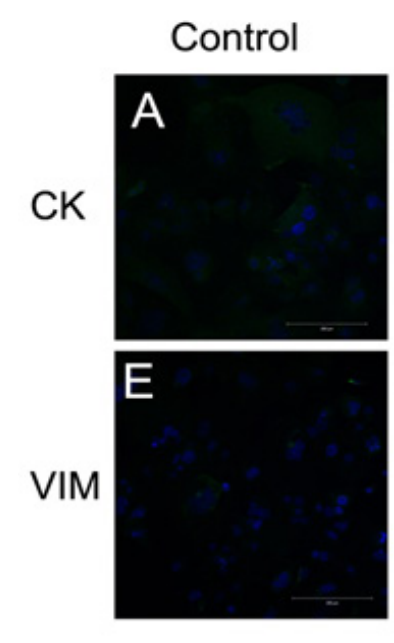

ToxA 1
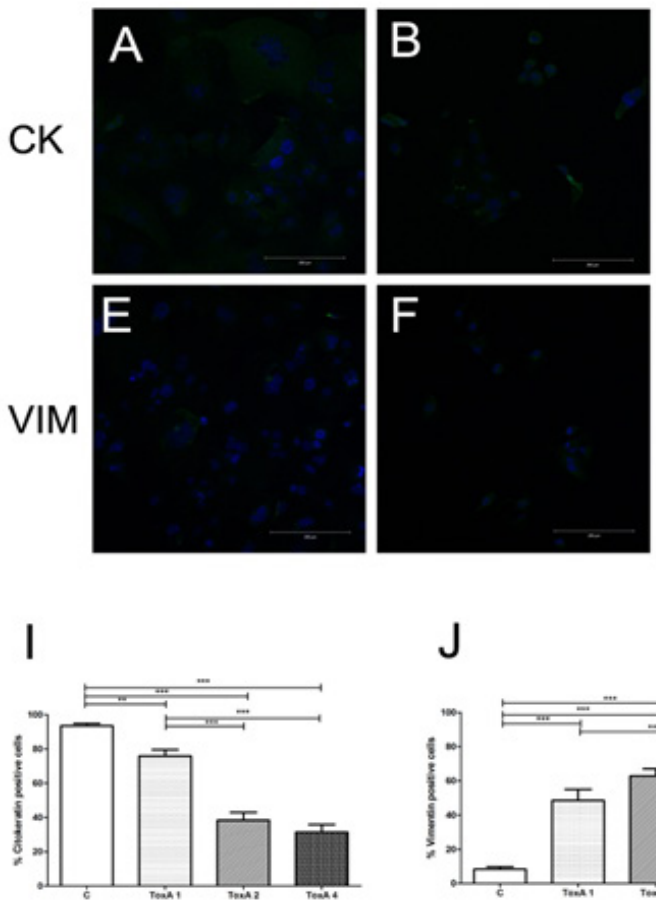

\section{$\mathrm{J}$}

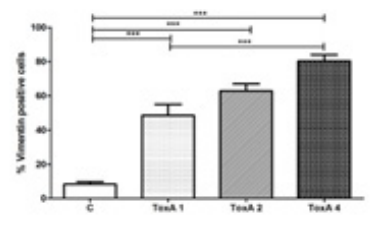

ToxA 2
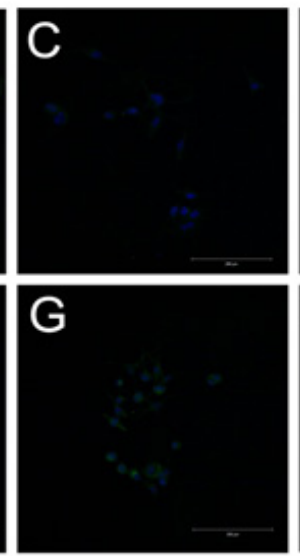

\section{ToxA 4}

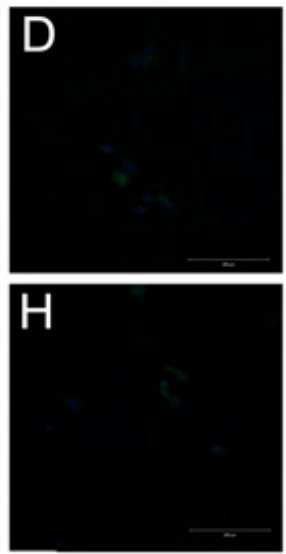

$\mathrm{K}$

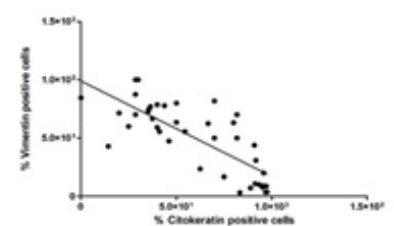

Figure 1. Rho GTPases are Important to Cytodifferentiation of Oral Squamous Cell Carcinoma Cell Line. Confocal analysis from a single section. Nuclei stained with DAPI (blue). Effects of inhibition of Rho GTPases with a broad spectrum inhibitor, Clostridium difficile Toxin A on SCC-4 cells: cytokeratin stain (green) control SCC-4 cells (a) and treated cells at $1 \mu \mathrm{g} / \mathrm{mL}$ (b), $2 \mu \mathrm{g} / \mathrm{mL}$ (c) and $4 \mu \mathrm{g} / \mathrm{mL}$ (d); vimentin stain (green): control SCC-4 cells (e), treated cells at $1 \mu \mathrm{g} / \mathrm{mL}(\mathrm{f}), 2 \mu \mathrm{g} / \mathrm{mL}$ (g) and $4 \mu \mathrm{g} / \mathrm{mL}(\mathrm{h})$. Morphometry of percentual of positive cells for citokeratin (i) and vimentin $(j),{ }^{*} p<0.001$ and $* * * p<0.0001$. Negative correlation of citokeratin and vimentin immunoexpression, $\mathrm{p}<0.0001(\mathrm{k})$. 

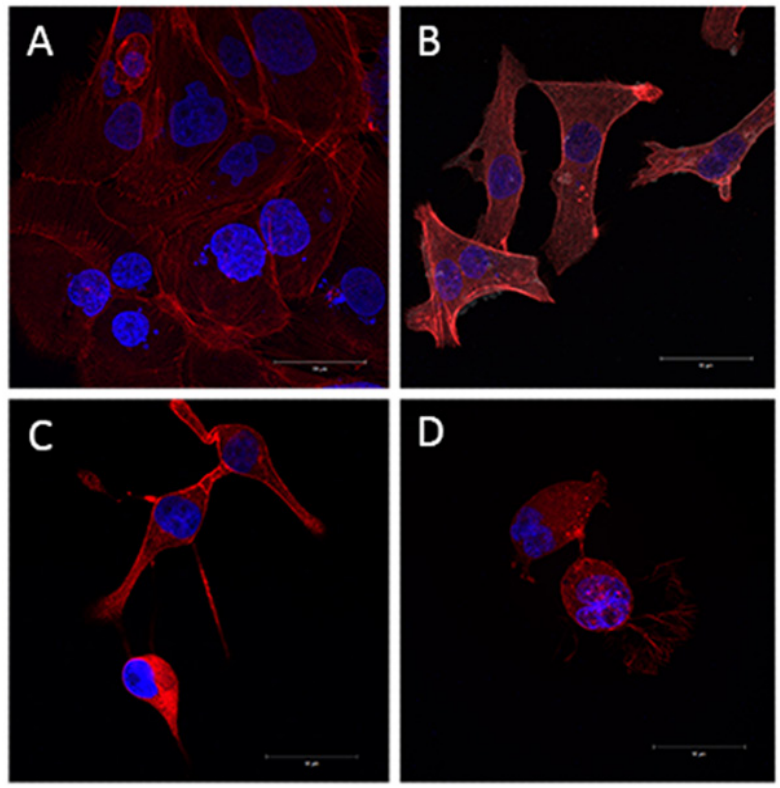

Figure 2. Rho GTPases are Important on Actin Cytoskeleton Organization of Oral Squamous Cell Carcinoma Cell Line. Sequential confocal images were compacted to show the threedimensional aspect. F-actin rhodamine-phalloidin stained (red) and nuclei DAPI stained (blue). Effects of inhibition of Rho GTPases Clostridium difficile Toxin A on SCC-4 cells actin cytoskeleton: control cells (a) and treated cells: $1 \mu \mathrm{g} / \mathrm{mL}$ (b), $2 \mu \mathrm{g} / \mathrm{mL}$ (c) and $4 \mu \mathrm{g} / \mathrm{mL}$ (d).

morphological changes when compared to control cells, treated cells presented a reduced cytoplasm, also F-actin and cortical actin polymerization was affected (Figure 2a-d).

\section{Discussion}

The results found in this study demonstrated the involvement of Rho GTPases proteins in the regulation of cytodifferentiation in oral squamous cell carcinoma cells. Epithelial cells express as marker cytokeratin and mesenchymal cells express vimentin, and the inhibition of Rho GTPases results in stimulation of cytodifferentiation characterized by increased expression of vimentin, an undifferentiated cells marker (Kalluri and Weinberg, 2009). In this study, the cytodifferentiation of SCC-4 cells was affected, decreasing cytokeratin and increasing vimentin immunoexpression, and results showed that the higher the amount of vimentin, the lower the amount of cytokeratin after the Rho GTPases inhibition for 24 hours. Therefore, an inhibition of Rho GTPases results in stimulation of cytodifferentiation characterized by increased expression of vimentin, an undifferentiated cells marker. In this study, the importance of Rho GTPases was demonstrated by their inhibition with Clostridium difficile Toxin A (broad spectrum inhibitor of the Rho GTPases family) treatment. Clostridium difficile Toxin A exerts an inhibitory effect on all Rho GTPases, and each of them plays a specific role (Zheng et al., 2006).

Head and neck SCC cell lines have high levels of constitutive Rac1 activated that are important to regulate cell invasion, however levels of GTP-RhoA and
GTP-Cdc42 were restricted (Patel et al., 2007) and RhoC expression was increased then normal oral epithelium (Kleer et al., 2006). RhoC expression were reduced in tongue SCC cells transfected with ectopic miR-138, and led cells to and changed morphology and increased cell migration and invasion (Jiang et al., 2010).

The work with immortalized culture makes it possible to manipulate signaling pathways by applying drugs under controlled conditions to analyze biological processes involved with tumorigenesis. On the other hand, it is not possible to understand the interference of various stimuli received by the tumor cell in its microenvironment in vivo. Although this study had not used techniques to detect which member of the family of Rho GTPases regulated the biological processes studied, results demonstrated that Rho GTPases are involved on regulation of cytodifferentiation of OSCC cell line. Future studies may elucidate the effect of chemotherapy on specific small GTPases proteins on cytodifferentiation of OSCC cell line.

\section{Acknowledgements}

We are grateful for financial support of Fundação de Amparo à Pesquisa do Estado de Minas Gerais - FAPEMIG (APQ-02333-18) and Coordenação de Aperfeiçoamento de Pessoal de Nível Superior - CAPES (scholarship).

\section{References}

Bhave SL, Teknos TN, Pan Q (2011). Molecular parameters of head and neck cancer metastasis. Crit Rev Eukaryot Gene Expr, 21, 143-53.

Fazeli Z, Pourhoseingholi MA, Pourhoseingholi A, et al (2011). Mortality of oral cavity cancer in Iran. Asian Pac J Cancer Prev, 12, 2763-66.

Jaffe ES (2009). The 2008 WHO classification of lymphomas: implications for clinical practice and translational research. Hematol Am Soc Hematol Educ Program, 2009, 523-31.

Jiang L, Liu X, Kolokythas A, et al (2010). Downregulation of the Rho GTPase signaling pathway is involved in the microRNA-138-mediated inhibition of cell migration and invasion in tongue squamous cell carcinoma. Int $J$ Cancer, 127, 505-12.

Kalluri R, Weinberg RA (2009). The basics of epithelial-mesenchymal transition. J Clin Invest, 119, 1420-28.

Kleer CG, Teknos TN, Islam M, et al (2006). RhoC GTPase expression as a potential marker of lymph node metastasis in squamous cell carcinomas of the head and neck. Clin Cancer Res, 12, 4485-90.

Patel V, Rosenfeldt HM, Lyons R, et al (2007). Persistent activation of Rac1 in squamous carcinomas of the head and neck: evidence for an EGFR/Vav2 signaling axis involved in cell invasion. Carcinogenesis, 28, 1145-52.

Rhodus NL, Kerr AR, Patel K (2014). Oral cancer: leukoplakia, premalignancy, and squamous cell carcinoma. Dent Clin North Am, 58, 315-40.

Ridley AJ, Hall A (1992). The small GTP-binding protein rho regulates the assembly of focal adhesions and actin stress fibers in response to growth factors. Cell, 70, 389-99.

Sadok A, Marshall CJ (2014). Rho GTPases: masters of cell migration. Small GTPases, 5, e297101-7.

Svensmark JH, Brakebusch C (2019). Rho GTPases in cancer: friend or foe?. Oncogene, [Epub ahead of print]. 
Nanci M Pinheiro et al

Zheng X, Baker H, Hancock WS, et al (2006). Proteomic analysis for the assessment of different lots of fetal bovine serum as a raw material for cell culture. Part IV. Application of proteomics to the manufacture of biological drugs. Biotechnol Prog, 22, 1294-1300.

\section{๑๐}

This work is licensed under a Creative Commons AttributionNon Commercial 4.0 International License. 